\title{
Impact of cardiovascular risk factors on myocardial work-insights from the STAAB cohort study
}

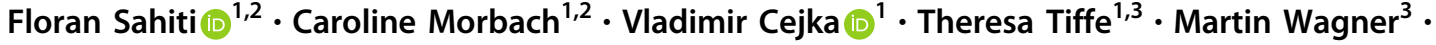 \\ Felizitas A. Eichner ${ }^{1,3} \cdot$ Götz Gelbrich ${ }^{1,3,4} \cdot$ Peter U. Heuschmann ${ }^{1,3,4} \cdot$ Stefan Störk $\mathbb{D}^{1,2}$
}

Received: 24 September 2020 / Revised: 25 January 2021 / Accepted: 5 February 2021 / Published online: 2 March 2021

(c) The Author(s) 2021. This article is published with open access

\begin{abstract}
Myocardial work is a new echocardiography-based diagnostic tool, which allows to quantify left ventricular performance based on pressure-strain loops, and has been validated against invasively derived pressure-volume measurements. Myocardial work is described by its components (global constructive work [GCW], global wasted work [GWW]) and indices (global work index [GWI], global work efficiency [GWE]). Applying this innovative concept, we characterized the prevalence and severity of subclinical left ventricular compromise in the general population and estimated its association with cardiovascular (CV) risk factors. Within the Characteristics and Course of Heart Failure STAges A/B and Determinants of Progression (STAAB) cohort study we comprehensively phenotyped a representative sample of the population of Würzburg, Germany, aged 30-79 years. Indices of myocardial work were determined in 1929 individuals (49.3\% female, mean age $54 \pm 12$ years). In multivariable analysis, hypertension was associated with a mild increase in GCW, but a profound increase in GWW, resulting in higher GWI and lower GWE. All other CV risk factors were associated with lower GCW and GWI, but not with GWW. The association of hypertension and obesity with GWI was stronger in women. We conclude that traditional CV risk factors impact selectively and gender-specifically on left ventricular myocardial performance, independent of systolic blood pressure. Quantifying active systolic and diastolic compromise by derivation of myocardial work advances our understanding of pathophysiological processes in health and cardiac disease.
\end{abstract}

\section{Introduction}

Myocardial work (MyW) is a novel echocardiographic method allowing to noninvasively determine total active

These authors contributed equally: Peter U. Heuschmann, Stefan Störk

Supplementary information The online version contains supplementary material available at https://doi.org/10.1038/s41371021-00509-4.

Stefan Störk

Stoerk_S@ukw.de

1 Comprehensive Heart Failure Center, University Hospital and University of Würzburg, Würzburg, Germany

2 Department of Medicine I, University Hospital Würzburg, Würzburg, Germany

3 Institute of Clinical Epidemiology and Biometry, University of Würzburg, Würzburg, Germany

4 Clinical Trial Center, University Hospital Würzburg, Würzburg, Germany myocardial performance via its two components constructive and wasted MyW (Fig. 1) [1]. Following known concepts of estimation of left ventricular (LV) systolic function by afterload-adjusted parameters of fiber shortening [2], the derivation of $\mathrm{MyW}$ integrates information on myocardial deformation (by speckle-tracking longitudinal strain) and afterload by pressure-strain loops (PSL). As such, the energy-consuming phases of the cardiac cycle, i.e., systolic and early diastolic active MyW can be quantified (Fig. 1). This information can be derived segment-by-segment or expressed as a global value, i.e., global constructive and wasted MyW (GCW, GWW). Echocardiography-derived parameters of MyW showed a high correlation with invasive validation measurements $[1,3,4]$. MyW demands the imputation of systemic blood pressure; it is markedly less load-dependent compared to conventional measures of LV function as ejection fraction and global longitudinal strain (GLPS) $[1,5,6]$, and might thus overcome the disadvantage of these measures of overestimating LV dysfunction in individuals with increased afterload [6, 7]. MyW might therefore be 


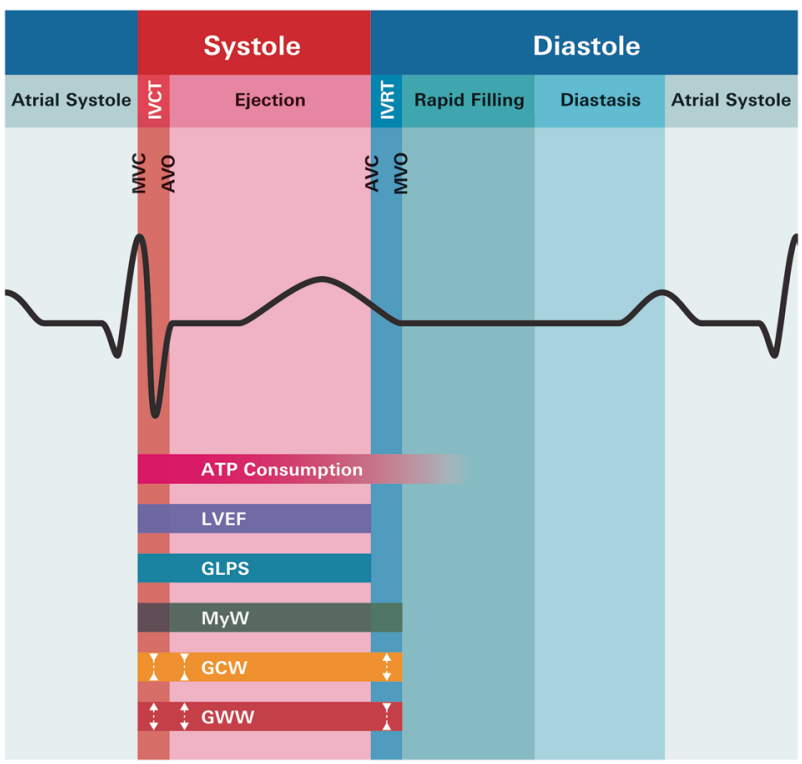

Fig. 1 Surrogate measures of left ventricular function in relation to the cardiac cycle and ATP consumption. Myocardial work includes total active myocardial work and allows us to differentiate constructive from wasted work components. LVEF left ventricular ejection fraction, GLPS global longitudinal peak strain, MyW myocardial work, GCW global constructive work, GWW global wasted work, MVC mitral valve closure, AVO aortic valve opening, AVC aortic valve closure, MVO mitral valve opening, IVRT isovolumic relaxation time, IVCT isovolumic contraction time, ATP adenosine triphosphate.

superior in detecting "real" subclinical LV dysfunction. Further, the derived PSL area was shown to reliably reflect the myocardial metabolic demand and oxygen consumption [1], thus, also providing insights into myocardial energetics.

Cardiovascular (CV) risk factors increase the risk to develop CV disease both indirectly, i.e., by altering the metabolic environment and homeostasis, or directly, i.e., by adversely affecting myocardial function [8]. As such, $\mathrm{CV}$ risk factors also associate with subclinical alterations in systolic and diastolic function and might accelerate conditions preceding heart failure with reduced and/or preserved ejection fraction [9-11]. Consistent with this view, changes of LV structure and function over time showed a more favorable pattern in the absence of $\mathrm{CV}$ risk factors [12].

Because the invasive assessment of pressure-volume loops is restricted to smaller patient samples due to the limited availability and the potential risks of an invasive procedure, echocardiography-based assessment of $\mathrm{MyW}$ is a readily available and noninvasive method. In the present analysis, we aimed to investigate the association between $\mathrm{CV}$ risk factors with $\mathrm{MyW}$ and its components in a large, well-characterized cohort derived from the general population.

\section{Methods}

\section{Population}

The Characteristics and Course of Heart Failure STAges A/ B and Determinants of Progression (STAAB) cohort study recruited and characterized a representative sample of the population of Würzburg, Germany, aged 30-79 years, free of symptomatic heart failure at inclusion. Details of the study design have been published previously [13]. The STAAB study complies with the Declaration of Helsinki and was approved by the Ethics Committee of the Medical Faculty, University of Würzburg (J-117.605-09/13). All participants provided written informed consent prior to any study examination. For the present analysis, we concentrated on the first half of the STAAB study population $(n=2473)$, which, due to a planned interim analysis [13], met sex and age stratification criteria of the total sample.

\section{Baseline examination}

Blood pressure (sitting position after 5 min of rest), body height and weight, smoking habits, and current medication were assessed according to standard operating procedures [13]. Laboratory measurements were performed at the Central Laboratory, University Hospital Würzburg, including fasting lipid profile, estimated glomerular filtration rate (eGFR), glycosylated haemoglobin (HbAlc), and plasma glucose levels.

$\mathrm{CV}$ risk factors included in the following analysis were obesity (body mass index $>30 \mathrm{~kg} / \mathrm{m}^{2}$ ) [14], dyslipidaemia (low-density lipoprotein [LDL] $>190 \mathrm{mg} / \mathrm{dl}$ [15], or on lipid-lowering medication), diabetes mellitus (HbA1c $>$ $6.5 \%$, or fasting plasma glucose $>7 \mathrm{mmol} / \mathrm{l}$, or plasma glucose $2 \mathrm{~h}$ after oral intake of $75 \mathrm{~g}$ glucose $>11.1 \mathrm{mmol} / \mathrm{l}$ [16] or on antidiabetic medication), hypertension (blood pressure $\geq 140 / 90 \mathrm{mmHg}$ [17] or on antihypertensive therapy), and smoking (current smoker or ex-smoker).

\section{Echocardiography and quality assurance}

All patients underwent standard transthoracic echocardiography using Vivid $\mathrm{S}^{\circ}$ (M4S Sector Array Transducer operating at $1.5-4.3 \mathrm{MHz}$, GE Healthcare, Horten, Norway). Two-dimensional images from the LV apical four-, two-, and three-chamber views were recorded with a frame rate of $50-80 \mathrm{~s}^{-1}$ and stored digitally. Image acquisition was performed by trained and certified sonographers on one echocardiography machine with consistent system presets according to a prespecified protocol. The characteristics and effectiveness of performance measures of the echocardiography quality assurance program have been published previously [18]. MyW analysis was performed by one 
researcher (F.S.). For assessment of observer variability, 20 randomly selected scans were read by the same observer twice, 2 weeks apart, for interobserver variability, the same scans were read by a second person (C.M.) blinded to the previous results. The inter-and intraobserver variability regarding MyW parameters was favorably low (Supplemental Table S1).

\section{Analysis of myocardial work}

For MyW analysis, a previously generated empiric normalized reference curve for LV pressure was used [1]. This reference curve was adjusted (a) by aligning valvular times as assessed by echocardiography and (b) by including blood pressure measured by cuff manometer as a surrogate of peak systolic LV pressure. Aortic and mitral valve closure and opening times were assessed by $\mathrm{CW}$ Doppler through the aortic valve and PW Doppler of the mitral valve. However, as the changes in heart rate during the examination would possibly affect the loop area, these time points were visually verified in the apical three-chamber view and manually adjusted where necessary. Two-dimensional images from the LV apical four-, two-, and three-chamber views were analyzed off-line using Automated Functional Imaging (EchoPAC ${ }^{\circ}$, Version 202, GE) to determine GLPS. Once GLPS was determined, the final adjustments for valve opening and/or closure times were done. We further provided the program with blood pressure values, to facilitate the derivation of the following parameters: $\mathrm{GCW}-\mathrm{mmHg} \%$, i.e., work performed during shortening in systole and adding negative work during lengthening in isovolumic relaxation, also defined as work contributing to pump function; global wasted work (GWW-mmHg\%), i.e., work performed during lengthening in systole or work performed during shortening against a closed aortic valve in isovolumic relaxation; global work index (GWI-mmHg\%), i.e., the total amount of work within the pressure-strain loop area calculated from mitral valve closure to mitral valve opening; GWE-\%, i.e., GCW/(GCW + GWW). All indices were calculated as the mean of respective segmental values (18segment model). Myocardial work was measured as detailed in a previous report of our research group [19]. We excluded subjects from further analysis if more than one LV segment was unsuitable for analysis due to poor tracking or suboptimal image quality. The latter was defined according to the American Society of Echocardiography as the inability to detect two or more contiguous segments in any of the three apical windows [20].

\section{Data analysis}

Statistical analysis was performed using SPSS (Version 25, SPSS Inc., Chicago, USA). Descriptives of continuous variables are provided as means (standard deviation), and categorical variables are presented as frequencies (percent). The variables were assessed for normality using the Shapiro-Wilk test. Differences in normally distributed variables were assessed using the $t$ test. Non normal distributed variables were assessed using the Mann-Whitney $U$ test. The relationship of MyW domains with sex, age, and $\mathrm{CV}$ risk factors was examined by analysis of covariance (ANCOVA). Chi-square tests were used to compare categorical variables. Observer variability was assessed using Bland-Altman 95\% limits of agreement. First, a univariable model for each CV risk factor was built and in a second step adjusted for age and sex. Furthermore, to examine the association of the $\mathrm{CV}$ risk factors with $\mathrm{MyW}$ indices independent of blood pressure, we additionally adjusted for systolic blood pressure. Then, interaction for sex was tested, and, in case of statistical significance, respective values for men and women were reported. All tests were performed two-sided. $P$ values $<0.05$ were considered statistically significant.

\section{Results}

The sample of the first-planned interim analysis comprised 2473 individuals. A total of $n=1929$ individuals (mean age $54 \pm 12$ years, $49.3 \%$ women) entered the present analysis. Reasons to exclude $n=544$ participants were the following: significant non-myocardial heart disease, $n=47$ (not in sinus rhythm, more than mild regurgitation, any stenosis of the mitral or aortic valve, symptomatic heart failure); missing blood pressure value, $n=16$; technical issues regarding the required views, $n=$ 143; suboptimal image quality, $n=338$. Comparing analyzed vs. excluded participants in a sensitivity analysis showed that non-analyzable subjects were more often female, slightly older, and exhibited a slightly worse clinical CV risk profile across the entire spectrum (Supplemental Table S2).

A subgroup of 439 participants (23\%) exhibited no CV risk factor. By contrast, 1490 participants $(77 \%)$ had at least one $\mathrm{CV}$ risk factor. Compared to the subgroup of participants with no CV risk factors, participants with $\geq 1$ $\mathrm{CV}$ risk factor were older, more often male, and had higher body mass index and less negative GLPS. There was no difference in LV ejection fraction (LVEF) between groups. Compared to women, men had lower LVEF and, consistently, less negative GLPS. Further, men exhibited higher body mass index, plasma glucose level, systolic blood pressure, and more often hypertension, diabetes, and dyslipidaemia. There was no sexspecific difference in the prevalence of smoking or obesity (Table 1). 
Table 1 Baseline characteristics of the study population.

\begin{tabular}{|c|c|c|c|c|c|c|c|}
\hline & $\begin{array}{l}\text { Total } \\
\text { sample } \\
n=1929\end{array}$ & $\begin{array}{l}\text { No } \mathrm{CV} \\
\text { risk factor } \\
n=439\end{array}$ & $\begin{array}{l}\geq 1 \mathrm{CV} \\
\text { risk factor } \\
n=1490\end{array}$ & $P$ value & $n=951$ & $\begin{array}{l}\text { Men } \\
n=978\end{array}$ & $P$ value \\
\hline Female sex & $951(49.3)$ & $248(56.4)$ & $703(47.1)$ & 0.001 & - & - & - \\
\hline Age [years] & $54(12)$ & $49(11)$ & $55(11)$ & $<0.001$ & $53(11)$ & $54(12)$ & 0.151 \\
\hline Body mass index $\left[\mathrm{kg} / \mathrm{m}^{2}\right]$ & $26(4)$ & $24(3)$ & $27(4)$ & $<0.001$ & $25(5)$ & $27(4)$ & $<0.001$ \\
\hline LVEF Simpson [\%] & $61(4)$ & $61(4)$ & $60(5)$ & 0.111 & $61(4)$ & $60(4)$ & $<0.001$ \\
\hline GLPS $[-\%]$ & $21(3)$ & $21(2)$ & $20(4)$ & $<0.001$ & $22(4)$ & $20(2)$ & $<0.001$ \\
\hline LVEDV & $99(25)$ & $97(25)$ & $100(25)$ & 0.062 & $86(19)$ & $113(23)$ & $<0.001$ \\
\hline LVESV & $39(11)$ & $38(10)$ & $40(12)$ & $<0.001$ & $33(9)$ & $45(11)$ & $<0.001$ \\
\hline LV mass $[\mathrm{g}]$ & $138(39)$ & $121(32)$ & $144(39)$ & $<0.001$ & $116(28)$ & $160(36)$ & $<0.001$ \\
\hline MV E wave [m/s] & $0.7(0.1)$ & $0.7(0.1)$ & $0.7(0.2)$ & 0.011 & $0.74(0.1)$ & $0.67(0.1)$ & $<0.001$ \\
\hline MV A wave [m/s] & $0.6(0.2)$ & $0.5(0.1)$ & $0.6(0.2)$ & $<0.001$ & $0.63(0.2)$ & $0.60(0.2)$ & 0.004 \\
\hline Mean E' $[\mathrm{m} / \mathrm{s}]$ & $0.09(0.03)$ & $0.11(0.02)$ & $0.09(0.03)$ & $<0.001$ & $0.09(0.02)$ & $0.10(0.3)$ & $<0.001$ \\
\hline $\mathrm{E} / \mathrm{E}$ & $8(3)$ & $7(2)$ & $8(3)$ & $<0.001$ & $8(3)$ & $7(2)$ & $<0.001$ \\
\hline IVRT [ms] & $94(18)$ & $89(14)$ & $95(18)$ & $<0.001$ & $90(15)$ & $96(19)$ & $<0.001$ \\
\hline Total cholesterol [mg/dl] & $208(38)$ & $202(34)$ & 209 (39) & 0.001 & $211(39)$ & $204(37)$ & $<0.001$ \\
\hline LDL cholesterol [mg/dl] & $122(34)$ & $117(30)$ & $124(35)$ & $<0.001$ & $121(35)$ & $124(33)$ & 0.059 \\
\hline eGFR [mL/min] & $87(15)$ & $90(14)$ & $86(15)$ & $<0.001$ & $87(15)$ & 87 (14) & 0.475 \\
\hline HbA1c [\%] & $5.5(0.6)$ & $5.3(0.3)$ & $5.5(0.6)$ & $<0.001$ & $5.5(0.6)$ & $5.5(0.6)$ & 0.435 \\
\hline Glucose value $[\mathrm{mmol} / \mathrm{L}]$ & $5.5(0.9)$ & $5.2(0.3)$ & $5.6(1.0)$ & $<0.001$ & $5.4(0.8)$ & $5.7(1.0)$ & $<0.001$ \\
\hline $\begin{array}{l}\text { Glucose value after } 2 \mathrm{~h} \\
{[\mathrm{mmol} / \mathrm{L}]}\end{array}$ & $6.0(1.7)$ & $5.6(1.3)$ & $6.1(1.8)$ & $<0.001$ & $6(1.6)$ & $6(1.8)$ & 0.511 \\
\hline $\begin{array}{l}\text { Systolic blood } \\
\text { pressure }[\mathrm{mmHg}]\end{array}$ & $130(18)$ & $122(11)$ & $133(18)$ & $<0.001$ & 127 (19) & $134(16)$ & $<0.001$ \\
\hline $\begin{array}{l}\text { Diastolic blood } \\
\text { pressure }[\mathrm{mmHg}]\end{array}$ & $78(10)$ & $75(7)$ & $80(10)$ & $<0.001$ & $77(10)$ & $80(9)$ & $<0.001$ \\
\hline Hypertension & $849(44)$ & - & $849(44)$ & - & 369 (39) & $480(49)$ & $<0.001$ \\
\hline Diabetes & $157(8)$ & - & $157(8)$ & - & $59(6)$ & $98(10)$ & 0.002 \\
\hline Smoking & 376 (19) & - & 376 (19) & - & $170(18)$ & $206(21)$ & 0.075 \\
\hline Obesity & $302(16)$ & - & 302 (16) & - & $140(15)$ & $162(17)$ & 0.266 \\
\hline Dyslipidaemia & $255(13)$ & - & $255(13)$ & - & $106(11)$ & $149(15)$ & 0.008 \\
\hline
\end{tabular}

Data are $n(\%)$ or mean (SD) or median (interquartiles).

$C V$ cardiovascular, $L V E F$ left ventricular ejection fraction, GLPS global longitudinal peak strain, $L V E D V$ left ventricular end-diastolic volume, $L V E S V$ left ventricular end-systolic volume, $M V$ mitral valve, IVRT isovolumic relaxation time, $L D L$ low-density lipoprotein, $e G F R$ estimated glomerular filtration rate, $H b A l c$ glycosylated haemoglobin.

\section{Myocardial work indices}

In the group with $\geq 1 \mathrm{CV}$ risk factor we found markedly higher GWW, but only slightly higher corresponding GCW. Thus, the complementary ratios GWI and GWE were changed accordingly, i.e., increased GWI and decreased GWE, when compared to the subgroup with no $\mathrm{CV}$ risk factors. We observed significant yet minor differences between men and women, $3 \%$ for GCW and 5\% for GWI, respectively. Further, in both subgroups with and without CV risk factors, women had significantly higher GWI when compared to men, whereas no such sex-related difference was apparent for GWW (Table 2).

\section{Association of CV risk factors with myocardial work indices}

\section{Global constructive work}

GCW was positively associated with systolic blood pressure, cholesterol, glucose level after $2 \mathrm{~h}$, hypertension, and inversely associated with body mass index, obesity, and smoking (Table 3). After adjustment for age and sex, GCW 
Table 2 Myocardial work characteristics of the study population according to risk factors and sex.

\begin{tabular}{lcllrrrr}
\hline & Total sample & No CV risk factor & $\begin{array}{l}\geq \text { CV risk factor } \\
n=1929\end{array}$ & $\begin{array}{l}P \text { value } \\
n=439\end{array}$ & $\begin{array}{l}\text { Women } \\
n=951\end{array}$ & $\begin{array}{l}\text { Men } \\
n=978\end{array}$ \\
\hline GCW [mmHg\%] & $2505(428)$ & $2440(334)$ & $2526(459)$ & $<0.001$ & $2550(439)$ & $2465(427)$ \\
GWW [mmHg\%] & $82(58-119)$ & $75(54-109)$ & $85(60-123)$ & $<0.001$ & $83(60-120)$ & $82(57-118)$ & 0.685 \\
GWI [mmHg\%] & $2277(396)$ & $2224(310)$ & $2293(416)$ & 0.001 & $2340(408)$ & $2216(373)$ & $<0.001$ \\
GWE [\%] & $96(95-97)$ & $96(95-97)$ & $96(94-97)$ & $<0.001$ & $96(95-97)$ & $96(94-97)$ & 0.093 \\
\hline
\end{tabular}

Data are $n(\%)$ or mean (SD) or median (interquartiles).

$C V$ cardiovascular, $G C W$ global constructive work, $G W W$ global wasted work, GWI global work index, GWE global work efficiency.

Table 3 Quantitative impact of CV risk factors on global constructive work (GCW), measured in $\mathrm{mmHg} \%$.

\begin{tabular}{|c|c|c|c|c|c|c|c|c|}
\hline & \multicolumn{2}{|l|}{ Univariable model } & \multirow{2}{*}{$\begin{array}{l}\text { Interaction } \\
\text { with sex } \\
P \text { value }\end{array}$} & \multicolumn{3}{|c|}{ Adjusted for age and sex } & \multicolumn{2}{|c|}{$\begin{array}{l}\text { Adjusted for age, sex, systolic blood } \\
\text { pressure }\end{array}$} \\
\hline & $\Delta(95 \% \mathrm{CI})$ & $P$ value & & Sex & $\Delta(95 \% \mathrm{CI})$ & $P$ value & $\Delta(95 \% \mathrm{CI})$ & $P$ value \\
\hline Body mass index $\left[\mathrm{kg} / \mathrm{m}^{2}\right]$ & $-7(-11$ to -2$)$ & 0.004 & 0.005 & $\begin{array}{l}\mathrm{M} \\
\mathrm{F}\end{array}$ & $\begin{array}{l}-17(-24 \text { to }-10)^{\mathrm{a}} \\
-4(-10 \text { to }+2)\end{array}$ & $\begin{array}{r}<0.001 \\
0.154\end{array}$ & $-19(-22$ to -16$)$ & $<0.001$ \\
\hline Systolic blood pressure $[\mathrm{mmHg}]$ & $+17(+16$ to +17$)$ & $<0.001$ & 0.376 & All & $+18(+18$ to +19$)$ & $<0.001$ & - & - \\
\hline Total cholesterol [mg/dl] & $+0.9(+0.3$ to +1$)$ & 0.001 & 0.466 & All & $+0.3(-0.2$ to +0.8$)$ & 0.296 & - & - \\
\hline LDL cholesterol [mg/dl] & $+0.3(-0.3$ to +0.8$)$ & 0.319 & 0.420 & All & $-0.09(-0.6$ to +0.5$)$ & 0.758 & - & - \\
\hline $\mathrm{HbA1c}[\%]$ & $+11(-24$ to +45$)$ & 0.552 & 0.272 & All & $-59(-95$ to -23$)$ & 0.001 & $-97(-122$ to -72$)$ & $<0.001$ \\
\hline Glucose level $[\mathrm{mmol} / \mathrm{L}]$ & $+4(-15$ to +24$)$ & 0.662 & 0.493 & All & $-11(-31$ to +9$)$ & 0.226 & - & - \\
\hline Glucose level after $2 \mathrm{~h}[\mathrm{mmol} / \mathrm{L}]$ & $+36(+23$ to +49$)$ & $<0.001$ & 0.685 & $\begin{array}{l}\text { All } \\
\text { All }\end{array}$ & $+25(+12$ to +39$)$ & $<0.001$ & $\begin{array}{l}\mathrm{M}:+3(-9 \text { to }+16) \\
\mathrm{F}:-17(-31 \text { to }-2)^{\mathrm{b}}\end{array}$ & $\begin{array}{l}0.603 \\
0.028\end{array}$ \\
\hline Diabetes & $-13(-83$ to +57$)$ & 0.718 & 0.312 & All & $-80(-150$ to -11$)$ & 0.024 & $-161(-210$ to -113$)$ & $<0.001$ \\
\hline Hypertension & $+303(+267$ to +339$)$ & $<0.001$ & 0.143 & All & $+290(+250$ to +331$)$ & $<0.001$ & - & - \\
\hline Smoking & $-186(-234$ to -139$)$ & $<0.001$ & 0.968 & All & $-160(-206$ to -113$)$ & $<0.001$ & $-69(-102$ to -36$)$ & $<0.001$ \\
\hline Obesity & $-99(-151$ to -46$)$ & $<0.001$ & 0.527 & All & $-123(-174$ to -72$)$ & $<0.001$ & $\begin{array}{l}\text { M: }-137(-185 \text { to }-89)^{b} \\
\text { F: }-229(-281 \text { to }-178)\end{array}$ & $\begin{array}{l}<0.001 \\
<0.001\end{array}$ \\
\hline Dyslipidaemia & $-16(-73$ to +40$)$ & 0.573 & 0.758 & All & $-98(-155$ to -41$)$ & 0.001 & $-94(-134$ to -54$)$ & $<0.001$ \\
\hline
\end{tabular}

Estimates were derived from ANCOVA models and report the strength of association of individual CV risk factors (per unit) on GCW as absolute difference with respective $95 \%$ confidence interval. E.g., a positive increment in body mass index of $1 \mathrm{~kg} / \mathrm{m}^{2}$ was associated with a $7 \mathrm{mmHg} \%$ decrement of GCW. Sex-specific associations are reported only ifinteraction with sex yielded a $p$ value $<0.05$.

${ }^{a}$ Interaction with sex was statistically significant after adjusting for age and sex.

${ }^{\mathrm{b}}$ After adjustment for systolic blood pressure, there was a significant interaction with sex. $L D L$ low-density lipoprotein, $H b A l c$ glycosylated haemoglobin.

was associated with systolic blood pressure, glucose level, and hypertension. Higher body mass index, diabetes, smoking, obesity, and dyslipidaemia were significantly associated with lower GCW. After additional adjustment for systolic blood pressure, GCW remained inversely associated with body mass index, obesity, HbA1c, glucose level after $2 \mathrm{~h}$, diabetes mellitus, smoking, and dyslipidaemia. Further, the association of GCW with obesity was more pronounced in women when compared to men.

\section{Global wasted work}

GWW was positively associated with systolic blood pressure, hypertension, cholesterol, dyslipidaemia, diabetes mellitus, and glucose level. After adjustment for age and sex, systolic blood pressure and hypertension remained associated with higher GWW (Table 4).

\section{Global work index}

GWI was inversely associated with body mass index, obesity, HbA1c, smoking, and positively associated with systolic blood pressure, hypertension, cholesterol, glucose level after $2 \mathrm{~h}$ (Table 5). After adjustment for age and sex, GWI was inversely associated with body mass index (men only), obesity, HbA1c, smoking, dyslipidaemia, and positively associated with glucose level after $2 \mathrm{~h}$, systolic blood pressure, hypertension (the association was more pronounced in women). After additional adjustment for systolic blood pressure, an inverse association with body mass index 
Table 4 Quantitative impact of CV risk factors on global wasted work (GWW), measured in $\mathrm{mmHg} \%$.

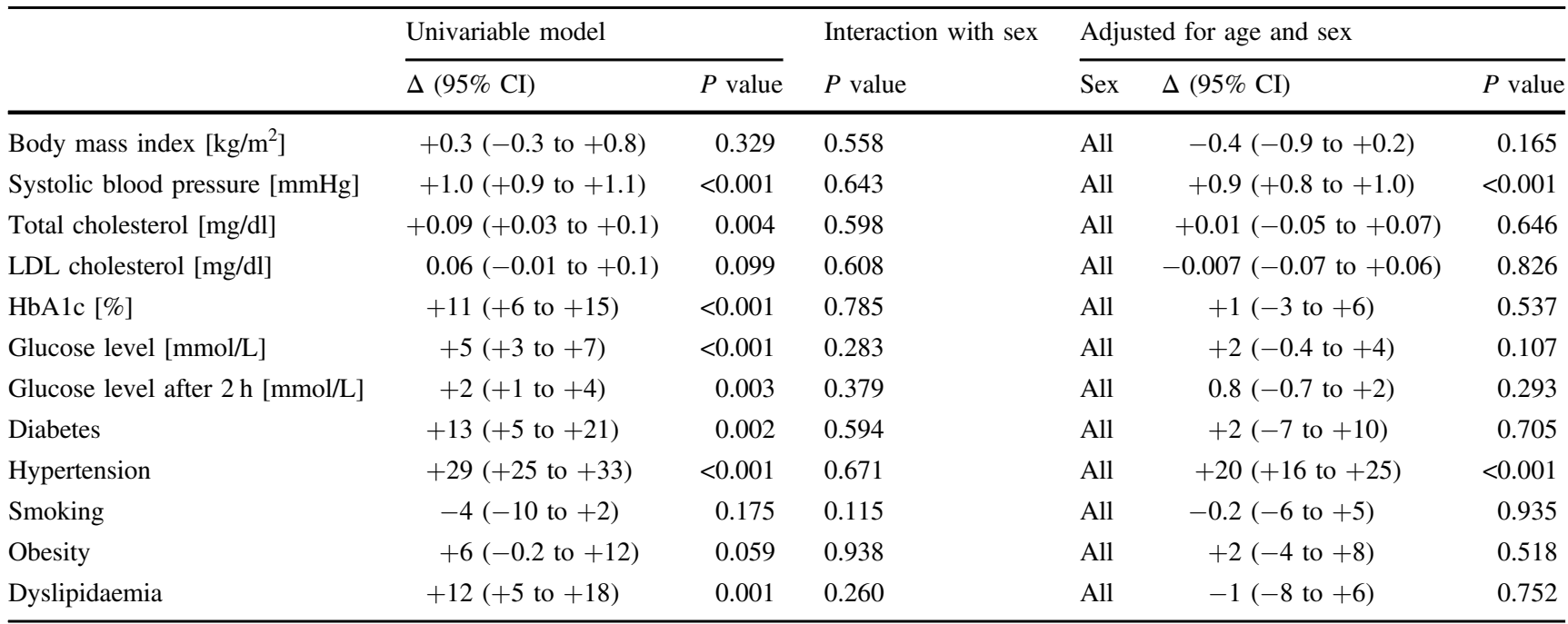

For interpretation of estimates and abbreviations please refer to the legend of Table 3.

Table 5 Quantitative impact of $\mathrm{CV}$ risk factors on global work index (GWI), measured in $\mathrm{mmHg} \%$.

\begin{tabular}{|c|c|c|c|c|c|c|c|c|}
\hline & \multicolumn{2}{|l|}{ Univariable model } & \multirow{2}{*}{$\begin{array}{l}\text { Interaction } \\
\text { with sex } \\
P \text { value }\end{array}$} & \multicolumn{3}{|c|}{ Adjusted for age and sex } & \multicolumn{2}{|c|}{$\begin{array}{l}\text { Adjusted for age, sex, systolic blood } \\
\text { pressure }\end{array}$} \\
\hline & $\Delta(95 \% \mathrm{CI})$ & $P$ value & & Sex & $\Delta(95 \% \mathrm{CI})$ & $P$ value & $\Delta(95 \% \mathrm{CI})$ & $P$ value \\
\hline Body mass index $\left[\mathrm{kg} / \mathrm{m}^{2}\right]$ & $-5(-9$ to -1$)$ & 0.019 & 0.002 & $\begin{array}{l}\mathrm{M} \\
\mathrm{F}\end{array}$ & $\begin{array}{l}-13(-19 \text { to }-7)^{\mathrm{a}} \\
-0.1(-5 \text { to }+5)\end{array}$ & $\begin{array}{r}<0.001 \\
0.968\end{array}$ & $-14(-17$ to -11$)$ & $<0.001$ \\
\hline Systolic blood pressure $[\mathrm{mmHg}]$ & $+14(+14$ to +15$)$ & $<0.001$ & 0.877 & All & $+17(+16$ to +17$)$ & $<0.001$ & - & - \\
\hline Total cholesterol [mg/dl] & $+0.8(+0.3$ to +1$)$ & 0.001 & 0.862 & All & $+0.3(-0.1$ to +0.8$)$ & 0.163 & - & - \\
\hline LDL cholesterol [mg/dl] & $+0.2(-0.3$ to +0.7$)$ & 0.481 & 0.794 & All & $-0.005(-0.5$ to +0.5$)$ & 0.984 & - & - \\
\hline $\mathrm{HbA1c}[\%]$ & $-2(-34$ to +30$)$ & 0.917 & 0.435 & All & $-46(-79$ to -12$)$ & 0.008 & $-80(-104$ to -56$)$ & $<0.001$ \\
\hline Glucose level [mmol/L] & $-3(-21$ to +16$)$ & 0.776 & 0.974 & All & $-8(-27$ to +10$)$ & 0.383 & - & - \\
\hline Glucose level after $2 \mathrm{~h}[\mathrm{mmol} / \mathrm{L}]$ & $+31(+18$ to +43$)$ & $<0.001$ & 0.985 & All & $+24(+12$ to +37$)$ & $<0.001$ & - & - \\
\hline Diabetes & $-20(-84$ to +45$)$ & 0.552 & 0.696 & All & $-53(-118$ to +12$)$ & 0.108 & - & - \\
\hline Hypertension & $+253(+219$ to +287$)$ & $<0.001$ & 0.046 & $\begin{array}{l}\mathrm{M} \\
\mathrm{F}\end{array}$ & $\begin{array}{l}+240(+190 \text { to }+288)^{\mathrm{a}} \\
+307(+256 \text { to }+358)\end{array}$ & $\begin{array}{l}<0.001 \\
<0.001\end{array}$ & - & - \\
\hline Smoking & $-160(-204$ to -116$)$ & $<0.001$ & 0.827 & All & $-140(-184$ to -97$)$ & $<0.001$ & $-58(-90$ to -26$)$ & $<0.001$ \\
\hline Obesity & $-82(-131$ to -34$)$ & 0.001 & 0.349 & All & $-95(-143$ to -48$)$ & $<0.001$ & $\begin{array}{l}\mathrm{M}:-115(-161 \text { to }-69)^{\mathrm{b}} \\
\mathrm{F}:-184(-233 \text { to }-134)\end{array}$ & $\begin{array}{l}<0.001 \\
<0.001\end{array}$ \\
\hline Dyslipidaemia & $-30(-82$ to +22$)$ & 0.256 & 0.908 & All & $-77(-130$ to -23$)$ & 0.005 & $-73(-111$ to -35$)$ & $<0.001$ \\
\hline
\end{tabular}

For interpretation of estimates and abbreviations please refer to the legend of Table 3 .

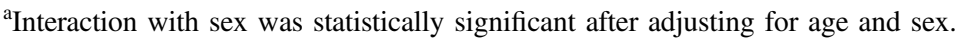

${ }^{\mathrm{b}}$ After adjustment for systolic blood pressure, there was a significant interaction with sex.

(either sex), HbA1c, obesity, dyslipidaemia, and smoking remained.

\section{Global work efficiency}

GWE was inversely associated with systolic blood pressure, hypertension, diabetes, HbA1c, glucose level, body mass index, obesity, cholesterol, and dyslipidaemia (Table 6). After adjustment for age and sex, inverse associations remained for systolic blood pressure, $\mathrm{HbA} 1 \mathrm{c}$, glucose level, diabetes mellitus, smoking, and obesity. This pattern was preserved after additional adjustment for systolic blood pressure.

\section{Discussion}

The current study investigated a well-characterized representative sample of the general population, aged 30-79 years, balanced for age and sex. We focused on the multifaceted associations of MyW, a novel echocardiographic approach quantifying active myocardial performance, with 


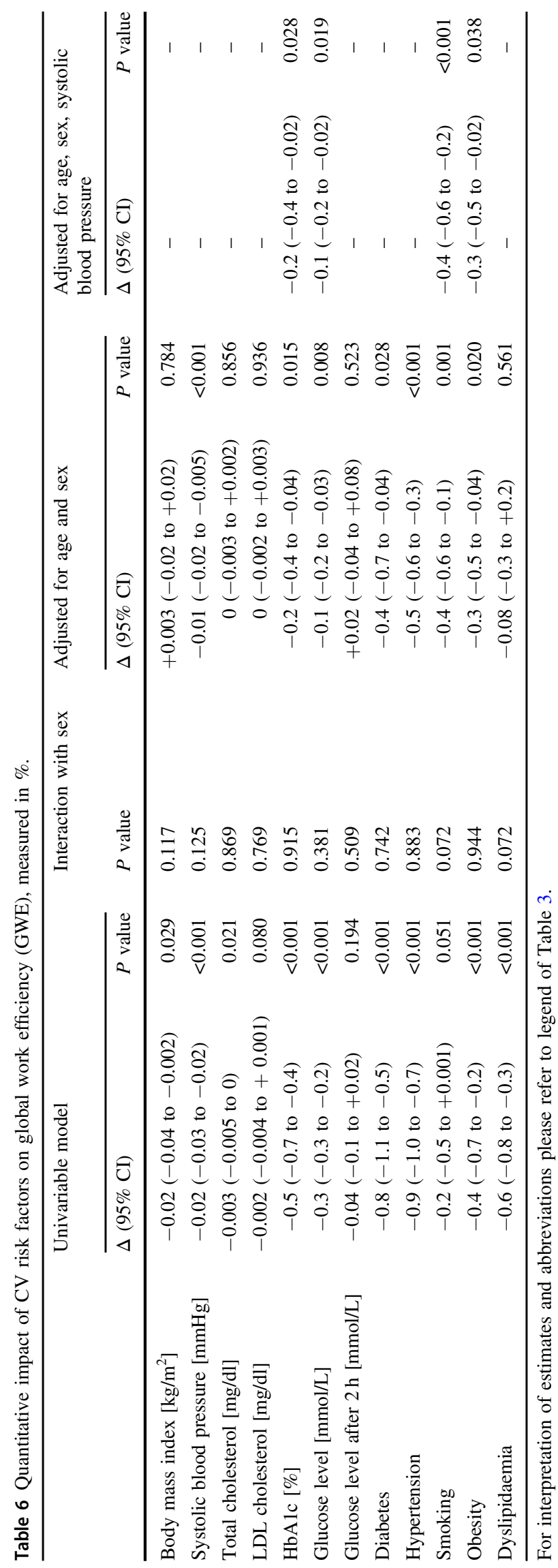

major CV risk factors and report three major findings. First, individuals exhibiting at least one risk factor had higher levels of all MyW domains except for work efficiency. This effect, compatible with a higher energy consumption during both the active systolic and early diastolic phase, was carried by an imbalanced increase in GWW resulting in lower work efficiency. Whereas GCW was higher in women compared to men, no such difference was found for GWW. Second, alterations in myocardial work were mainly induced by higher systolic blood pressure and pre-existing hypertension. In particular, hypertension showed the strongest association with all $\mathrm{MyW}$ domains and was the only risk factor with a pronounced and independent impact on GWW. Third, diabetes mellitus, obesity, dyslipidaemia, and smoking showed a pattern of isolated reduction in GCW and GWI, independent from systolic blood pressure, and did not affect GWW.

\section{Hypertension}

Systemic hypertension is known to induce LV hypertrophy, and ultimately heart failure. Experimental models of human hypertensive hypertrophy in rats showed that myocardial efficiency decreases over time, and the disease aggravates from compensated hypertrophy to heart failure [21]. In a large cohort of hypertensive participants, LV hypertrophy was associated with depressed myocardial mechanoenergetic efficiency which, in turn, predicted adverse outcome [22]. Previous analyses of our cohort [10] suggested a sex-specific sensitivity of the myocardium to individual CV risk factors, such as hypertension and dyslipidaemia. The present analysis showed an adverse effect of hypertension on the GWI in either sex, which consistently was stronger in women when compared to men. Further, previous studies in smaller groups of patients with hypertension reported an increase in GCW and GWW but found no changes in GWE [23, 24]. Along these lines, the NORRE consortium [25] also found GWI and GCW to be associated with systolic blood pressure. Our results confirm that hypertension was associated with higher constructive and wasted myocardial work, but revealed an adverse impact on work efficiency. A lower myocardial work efficiency, in line with lower myocardial mechano-energetic efficiency as described previously [22], might be the underlying pathomechanism driving symptomatic heart failure in hypertensive heart disease.

Systolic blood pressure and hypertension were the only risk factor studied enhancing wasted work. GWW by itself is very intriguing comprising the myocardium's loss of energy during a heart cycle. This loss, according to Boe et al. [5], is an additional mechanical burden to the myocardium and may thus induce the accelerated development of heart failure. However, the exact mechanisms are not 
well understood. Loading conditions seem to interfere on wall tension by increasing wall stress and stiffness [26] and subsequently by increasing wasted work. This translates into increased myocardial oxygen demand and successively cardiac work augmentation. Lam et al. [27] found that in the early stages of hypertension, the antihypertensive therapy reduced arterial and LV systolic stiffness and lowered the ventricular-arterial coupling ratio. Thus, although total cardiac work was reduced, efficiency improved. We consistently found hypertension associated with higher total myocardial work but lower efficiency, which was explained by a disproportional increase of wasted work. Consequently, we would expect antihypertensive therapy to lower total myocardial work and optimize GWE by reducing GWW. Detailed assessment of hypertensive patients using echocardiography derived MyW indices might further enlighten the pathophysiology of hypertensive heart disease and identify potential treatment targets.

\section{Diabetes mellitus}

Diabetes mellitus portends an increased risk for subsequent development of heart failure, and death [28]. Besides the development of CVD [28], diabetes mellitus seems also to directly affect the myocardium. Impaired GLS was found an early sign of diabetic heart disease [29], even in asymptomatic normotensive diabetes patients [30, 31], and was associated with adverse clinical outcomes [32]. In nondiabetic individuals, increased insulin resistance as a measure of glycaemic status was associated with impaired mechano-energetic efficiency [33]. In our study, diabetes mellitus and $\mathrm{HbA} 1 \mathrm{c}$ were negatively associated with GCW and GWI. This association became even stronger after adjusting for systolic blood pressure, suggesting that diabetes and HbA1c affect systolic dysfunction independent of systolic blood pressure. After adjusting for blood pressure, we found an association of MyW efficiency with HbAlc but not with diabetes mellitus. MyW efficiency seems to be more affected by the level of chronic hyperglycemia as evidenced by HbA1c compared to the sole presence of diabetes mellitus. These findings emphasize the importance of enforcing blood sugar optimization to prevent cardiac damage in patients with diabetes mellitus.

\section{Obesity, dyslipidaemia, and smoking}

Obesity, dyslipidaemia, and smoking are established risk factors for CV disease and heart failure [34-36]. Obesity, like diabetes mellitus, is associated with subtle systolic dysfunction [37]. Further, both entities are associated with poor glycaemic control and hyperinsulinemia, which may lead to changes in myocardial metabolism and fibrosis $[38,39]$. Smoking is interrelated with inflammation, lipid abnormalities, and arterial stiffness which are prone to contribute to alterations in LV structure and function [40]. In our analysis, they revealed similar patterns of myocardial alteration by lowering GCW and GWI but without significant affection of GWW, independent from systolic blood pressure. Further, previous analyses of our cohort [10] found obesity adversely associated with myocardial deformation in either sex. In contrast, after adjustment for systolic blood pressure, myocardial work indices appeared more severely affected by obesity in women when compared to men. Further, these results strengthen the concept of sex-specific sensitivity of the myocardium to respective risk factors and should trigger further research in this field. The presence of CV risk factors in a sample of the general population free from heart failure seems to impact LV performance as assessed by $\mathrm{MyW}$ and reduce work efficiency through different pathways. MyW may potentially give new insights into the pathophysiology of different cardiac diseases, help to identify early abnormalities in LV function, and establish a more sensitive index for early stage dysfunction that opens the way to early preventive interventions.

\section{Strengths and limitations}

To the best of our knowledge, this study is the first to provide a comprehensive assessment of the association of $\mathrm{CV}$ risk factors with echocardiography-based $\mathrm{MyW}$ indices, derived from a large, well-characterized representative sample of the general population. Within the STAAB cohort study, blood pressure was measured in a sitting position after $5 \mathrm{~min}$ of rest during the same 3-h study visit, in agreement with international recommendations [17]. Ideally, for this analysis, blood pressure should have been measured during the echocardiographic examination. Hypertension as a major risk factor, had a key impact in this analysis, given its high prevalence and the haemodynamic impact on LV function, performance, and contractility. MyW method relies on the indirect measurement of brachial cuff pressure as a surrogate of invasively measured pressure, which might affect the accuracy of the estimation of the various work domains. However, the approach used in the present study was reported to yield good agreement with invasive measurements [1].

\section{Conclusion}

Individual CV risk factors selectively impact on constructive and wasted active myocardial function as measured by $\mathrm{MyW}$ domains. In particular, the heart in hypertension appears to operate at higher energy levels as indicated by both increased GCW and GWW, which results 
in lower work efficiency. This pathomechanism may drive the development of symptomatic heart failure in hypertensive heart disease. The other $\mathrm{CV}$ risk factors also adversely impact on GWE, predominantly by reducing GCW independent of systolic blood pressure. Quantifying active systolic and diastolic compromise by derivation of MyW holds promise to improve our understanding of pathophysiological processes in cardiac disease. Further studies are needed to evaluate the value of selected MyW parameters or a respective pattern of $\mathrm{MyW}$ indices to assess the current health status of an individual patient.

\section{Summary}

\section{What is known about the topic}

- Left ventricular ejection fraction and longitudinal strain are load-dependent and might thus overestimate left ventricular dysfunction. The reference standard to quantify ventricular dysfunction requires invasive haemodynamic assessment.

- "Myocardial work" represents a novel validated approach, which allows quantifying active myocardial performance by means of non-invasively derived echocardiographic pressure-strain loops.

- The components and indices of myocardial work are viewed as reliable surrogates of appropriate or disproportionate myocardial energy consumption.

\section{What this study adds}

- Cardiovascular risk factors adversely affect myocardial work, independent from systolic blood pressure, individually, cumulatively, and in a sex-specific manner.

- Hypertension profoundly compromises myocardial work, in particular by increasing global wasted work. The heart in hypertension appears to operate at higher energy levels, yet lower efficiency.

- Quantifying active systolic and diastolic domains by means of myocardial work holds promise to improve our understanding of pathophysiological processes in cardiac disease.

Acknowledgements We cordially thank the STAAB Consortium. Further, we greatly appreciate the time of all STAAB participants and their willingness to provide data to the study. We also thank the Mayor of the City of Würzburg and the local registration office for their sustained support of our study. We thank the entire study team, study nurses, technicians, data managers, and students for their efforts on the STAAB study. We also thank M. Ertl, G. Fette, and F. Puppe from the CHFC DataWarehouse, Institute of Informatics VI, University of Würzburg, as well as T. Ludwig, ICE-B, for diligent data management.
Author contributions Floran Sahiti analysis and interpretation of data, drafting of the paper, final approval of the paper submitted. Caroline Morbach analysis and interpretation of data, revising the manuscript critically for important intellectual content, final approval of the paper submitted. Vladimir Cejka analysis and interpretation of data, revising the paper critically for important intellectual content, final approval of the paper submitted. Theresa Tiffe analysis and interpretation of data, revising the paper critically for important intellectual content, final approval of the paper submitted. Martin Wagner analysis and interpretation of data, revising the paper critically for important intellectual content, final approval of the paper submitted. Felizitas Eichner analysis and interpretation of data, revising the paper critically for important intellectual content, final approval of the paper submitted. Götz, Gelbrich conception and design, analysis and interpretation of data, revising the paper critically for important intellectual content, final approval of the paper submitted. Peter U Heuschmann conception and design, interpretation of data, revising the paper critically for important intellectual content, final approval of the paper submitted. Stefan Störk conception and design, interpretation of data, revising the paper critically for important intellectual content, final approval of the paper submitted. We agree to be accountable for all aspects of the work ensuring that questions related to the accuracy or integrity of any part of the work are appropriately investigated and resolved. We fully disclose any relationship with industry.

Funding The study is supported by the German Ministry of Research and Education within the Comprehensive Heart Failure Center, Würzburg (BMBF 01EO1004 and 01EO1504). Floran Sahiti is supported by an $\mathrm{MD} / \mathrm{PhD}$ fellowship of the Interdisciplinary Center for Clinical Research (IZKF) of the Medical Faculty, University of Würzburg. Open Access funding enabled and organized by Projekt DEAL.

\section{Compliance with ethical standards}

Conflict of interest Floran Sahiti receives financial support from Interdisciplinary Center for Clinical Research (IZKF) Würzburg (MD/ $\mathrm{PhD}$ program scholarship). Caroline Morbach reports a research cooperation with the University of Würzburg and Tomtec Imaging Systems funded by a research grant from the Bavarian Ministry of Economic Affairs, Regional Development and Energy, Germany, speakers honorarium from Amgen and Tomtec, a travel grant from Orion Pharma and Alnylam, participation in Advisory and Patient Eligibility Boards sponsored by AKCEA, Alnylam, Pfizer and EBR Systems outside the submitted work. Vladimir Cejka none. Theresa Tiffe none. Martin Wagner none. Felizitas Eichner none. Götz Gelbrich reports a research cooperation with the University Hospital Würzburg and TomTec Imaging Systems funded by a research grant from the Bavarian Ministry of Economic Affairs, Regional Development and Energy, Germany, a grant from the German Research Council (DFG) as the senior biometrician of the FIND-AF II trial outside the submitted work. Peter Heuschmann reports research grants from German Ministry of Research and Education, European Union, Charité-Universitätsmedizin Berlin, Berlin Chamber of Physicians, German Parkinson Society, University Hospital Würzburg, Robert Koch Institute, German Heart Foundation, Federal Joint Committee (G-BA) within the Innovationfond, University Hospital Heidelberg (within RASUNOA-prime; RASUNOA-prime is supported by an unrestricted research grant to the University Hospital Heidelberg from Bayer, BMS, Boehringer-Ingelheim, Daiichi Sankyo), grants from Charité-Universitätsmedizin Berlin (within Mondafis; Mondafis is supported by an unrestricted research grant to the Charité from Bayer), from University Göttingen (within FIND-AF randomized; FIND-AF randomized is supported by an unrestricted research grant to the University Göttingen from Boehringer-Ingelheim), outside the 
submitted work. Stefan Störk reports research grants from the German Ministry of Education and Research, European Union, University Hospital Würzburg; participation in Advisory Boards for AstraZeneca, Bayer, Boehringer Ingelheim, Boston Scientific, Novartis, Pfizer, Thermo-Fisher; principal investigator in trials (co-) sponsored by Bayer, Boehringer-Ingelheim, Novartis, Pfizer; speaker honoraria by Astra-Zeneca, Bayer, Boehringer Ingelheim, Novartis, Pfizer, Servier, outside the submitted work

Publisher's note Springer Nature remains neutral with regard to jurisdictional claims in published maps and institutional affiliations.

Open Access This article is licensed under a Creative Commons Attribution 4.0 International License, which permits use, sharing, adaptation, distribution and reproduction in any medium or format, as long as you give appropriate credit to the original author(s) and the source, provide a link to the Creative Commons license, and indicate if changes were made. The images or other third party material in this article are included in the article's Creative Commons license, unless indicated otherwise in a credit line to the material. If material is not included in the article's Creative Commons license and your intended use is not permitted by statutory regulation or exceeds the permitted use, you will need to obtain permission directly from the copyright holder. To view a copy of this license, visit http://creativecommons. org/licenses/by/4.0/.

\section{References}

1. Russell K, Eriksen M, Aaberge L, Wilhelmsen N, Skulstad H, Remme EW, et al. A novel clinical method for quantification of regional left ventricular pressure-strain loop area: a non-invasive index of myocardial work. Eur Heart J. 2012;33:724-33.

2. Reichek N, Wilson J, St John Sutton M, Plappert TA, Goldberg S, Hirshfeld JW. Noninvasive determination of left ventricular endsystolic stress: validation of the method and initial application. Circulation 1982;65:99-108.

3. Russell K, Eriksen M, Aaberge L, Wilhelmsen N, Skulstad H, Gjesdal O, et al. Assessment of wasted myocardial work: a novel method to quantify energy loss due to uncoordinated left ventricular contractions. Am J Physiol Heart Circ Physiol. 2013;305: H996-1003.

4. Hubert A, Le Rolle V, Leclercq C, Galli E, Samset E, Casset C, et al. Estimation of myocardial work from pressure-strain loops analysis: an experimental evaluation. Eur Heart $\mathbf{J}$ Cardiovasc Imaging 2018;19:1372-9.

5. Boe E, Skulstad H, Smiseth OA. Myocardial work by echocardiography: a novel method ready for clinical testing. Eur Heart J Cardiovasc Imaging 2019;20:18-20.

6. Sletten OJ, Alen J, Khan FH, Larsen CK, Inoue K, Remme EW, Hisdal $\mathrm{J}$, et al. Myocardial work exposes afterload-dependent changes in strain. EuroEcho (ESC, Vienna, 2019).

7. Boe E, Russell K, Eek C, Eriksen M, Remme EW, Smiseth OA, et al. Non-invasive myocardial work index identifies acute coronary occlusion in patients with non-ST-segment elevation-acute coronary syndrome. Eur Heart $\mathrm{J}$ Cardiovasc Imaging 2015; 16:1247-55.

8. Petersen SE, Sanghvi MM, Aung N, Cooper JA, Paiva JM, Zemrak F, et al. The impact of cardiovascular risk factors on cardiac structure and function: Insights from the UK Biobank imaging enhancement study. PLoS ONE 2017;12: e0185114.

9. Heckbert SR, Post W, Pearson GD, Arnett DK, Gomes AS, Jerosch-Herold M, et al. Traditional cardiovascular risk factors in relation to left ventricular mass, volume, and systolic function by cardiac magnetic resonance imaging: the Multiethnic Study of Atherosclerosis. J Am Coll Cardiol. 2006;48:2285-92.

10. Morbach C, Walter BN, Breunig M, Liu D, Tiffe T, Wagner M, et al. Speckle tracking derived reference values of myocardial deformation and impact of cardiovascular risk factors-results from the population-based STAAB cohort study. PLoS ONE 2019; 14:e221888.

11. Dunlay SM, Weston SA, Jacobsen SJ, Roger VL. Risk factors for heart failure: a population-based case-control study. Am J Med. 2009;122:1023-8.

12. Liu CY, Lai S, Kawel-Boehm N, Chahal H, Ambale-Venkatesh B, Lima JAC, et al. Healthy aging of the left ventricle in relationship to cardiovascular risk factors: the Multi-Ethnic Study of Atherosclerosis (MESA). PLoS ONE 2017;12:e0179947.

13. Wagner M, Tiffe $T$, Morbach $C$, Gelbrich G, Stork S, Heuschmann PU, et al. Characteristics and course of heart failure stages A-B and determinants of progression-design and rationale of the STAAB cohort study. Eur J Prev Cardiol. 2017;24:468-79.

14. Fruhbeck G, Toplak H, Woodward E, Yumuk V, Maislos M, Oppert JM, et al. Obesity: the gateway to ill health-an EASO position statement on a rising public health, clinical and scientific challenge in Europe. Obes Facts 2013;6:117-20.

15. European Association for Cardiovascular P, Rehabilitation, Reiner Z, Catapano AL, De Backer G, Graham I, et al. ESC/EAS Guidelines for the management of dyslipidaemias: the Task Force for the management of dyslipidaemias of the European Society of Cardiology (ESC) and the European Atherosclerosis Society (EAS). Eur Heart J. 2011;32:1769-818.

16. Authors/Task Force M, Ryden L, Grant PJ, Anker SD, Berne C, Cosentino F, et al. ESC Guidelines on diabetes, pre-diabetes, and cardiovascular diseases developed in collaboration with the EASD: the Task Force on diabetes, pre-diabetes, and cardiovascular diseases of the European Society of Cardiology (ESC) and developed in collaboration with the European Association for the Study of Diabetes (EASD). Eur Heart J. 2013;34:3035-87.

17. Mancia G, Fagard R, Narkiewicz K, Redon J, Zanchetti A, Bohm M, et al. 2013 ESH/ESC guidelines for the management of arterial hypertension: the Task Force for the Management of Arterial Hypertension of the European Society of Hypertension (ESH) and of the European Society of Cardiology (ESC). Eur Heart J. 2013;34:2159-219.

18. Morbach C, Gelbrich G, Breunig M, Tiffe T, Wagner M, Heuschmann PU, et al. Impact of acquisition and interpretation on total inter-observer variability in echocardiography: results from the quality assurance program of the STAAB cohort study. Int J Cardiovasc Imaging 2018;34:1057-65.

19. Morbach C, Sahiti F, Tiffe T, Cejka V, Eichner FA, Gelbrich G, et al. Myocardial work-correlation patterns and reference values from the population-based STAAB cohort study. PLOS ONE 2020;15:e0239684.

20. Porter TR, Abdelmoneim S, Belcik JT, McCulloch ML, Mulvagh SL, Olson JJ, et al. Guidelines for the cardiac sonographer in the performance of contrast echocardiography: a focused update from the American Society of Echocardiography. J Am Soc Echocardiogr. 2014;27:797-810.

21. Han JC, Barrett CJ, Taberner AJ, Loiselle DS. Does reduced myocardial efficiency in systemic hypertensive-hypertrophy correlate with increased left-ventricular wall thickness? Hypertens Res. 2015;38:530-8.

22. de Simone G, Izzo R, Losi MA, Stabile E, Rozza F, Canciello G, et al. Depressed myocardial energetic efficiency is associated with increased cardiovascular risk in hypertensive left ventricular hypertrophy. J Hypertens. 2016;34:1846-53.

23. Chan J, Edwards NFA, Khandheria BK, Shiino K, Sabapathy S, Anderson B, et al. A new approach to assess myocardial work by 
non-invasive left ventricular pressure-strain relations in hypertension and dilated cardiomyopathy. Eur Heart $\mathrm{J}$ Cardiovasc Imaging 2019;20:31-9.

24. El Mahdiui M, van der Bijl P, Abou R, Ajmone Marsan N, Delgado V, Bax JJ. Global left ventricular myocardial work efficiency in healthy individuals and patients with cardiovascular disease. J Am Soc Echocardiogr. 2019;32:1120-7.

25. Manganaro R, Marchetta S, Dulgheru R, Sugimoto T, Tsugu T, Ilardi F, et al. Correlation between non-invasive myocardial work indices and main parameters of systolic and diastolic function: results from the EACVI NORRE study. Eur Heart J Cardiovasc Imaging 2020;21:533-41.

26. Kuznetsova T, D’Hooge J, Kloch-Badelek M, Sakiewicz W, Thijs $\mathrm{L}$, Staessen JA. Impact of hypertension on ventricular-arterial coupling and regional myocardial work at rest and during isometric exercise. J Am Soc Echocardiogr. 2012;25:882-90.

27. Lam CS, Shah AM, Borlaug BA, Cheng S, Verma A, Izzo J, et al. Effect of antihypertensive therapy on ventricular-arterial mechanics, coupling, and efficiency. Eur Heart J. 2013;34: 676-83.

28. Wild S, Roglic G, Green A, Sicree R, King H. Global prevalence of diabetes: estimates for the year 2000 and projections for 2030. Diabetes Care 2004;27:1047-53.

29. Ernande L, Bergerot C, Rietzschel ER, De Buyzere ML, Thibault H, Pignonblanc PG, et al. Diastolic dysfunction in patients with type 2 diabetes mellitus: is it really the first marker of diabetic cardiomyopathy? J Am Soc Echocardiogr. 2011;24:1268-75 e1.

30. Ng AC, Delgado V, Bertini M, van der Meer RW, Rijzewijk LJ, Shanks M, et al. Findings from left ventricular strain and strain rate imaging in asymptomatic patients with type 2 diabetes mellitus. Am J Cardiol. 2009; 104:1398-401.

31. Holland DJ, Marwick TH, Haluska BA, Leano R, Hordern MD, Hare JL, et al. Subclinical LV dysfunction and 10-year outcomes in type 2 diabetes mellitus. Heart 2015;101:1061-6.

32. Kristensen SL, Jhund PS, Lee MMY, Kober L, Solomon SD, Granger $\mathrm{CB}$, et al. Prevalence of prediabetes and undiagnosed diabetes in patients with HFpEF and HFrEF and associated clinical outcomes. Cardiovasc Drugs Ther. 2017;31:545-9.

33. Mancusi C, de Simone G, Best LG, Wang W, Zhang Y, Roman $\mathrm{MJ}$, et al. Myocardial mechano-energetic efficiency and insulin resistance in non-diabetic members of the Strong Heart Study cohort. Cardiovasc Diabetol. 2019;18:56.

34. Peterson LR, Waggoner AD, Schechtman KB, Meyer T, Gropler $\mathrm{RJ}$, Barzilai $\mathrm{B}$, et al. Alterations in left ventricular structure and function in young healthy obese women: assessment by echocardiography and tissue Doppler imaging. J Am Coll Cardiol. 2004;43:1399-404.

35. Vitarelli A, Martino F, Capotosto L, Martino E, Colantoni C, Ashurov $\mathrm{R}$, et al. Early myocardial deformation changes in hypercholesterolemic and obese children and adolescents: a 2D and 3D speckle tracking echocardiography study. Medicines 2014;93:e71.

36. Eng J, McClelland RL, Gomes AS, Hundley WG, Cheng S, Wu $\mathrm{CO}$, et al. Adverse left ventricular remodeling and age assessed with cardiac MR imaging: the multi-ethnic study of atherosclerosis. Radiology 2016;278:714-22.

37. Suto M, Tanaka H, Mochizuki Y, Mukai J, Takada H, Soga F, et al. Impact of overweight on left ventricular function in type 2 diabetes mellitus. Cardiovasc Diabetol. 2017;16:145.

38. Liedtke AJ, DeMaison L, Eggleston AM, Cohen LM, Nellis SH. Changes in substrate metabolism and effects of excess fatty acids in reperfused myocardium. Circ Res. 1988;62:535-42.

39. Kosmala W, Wong C, Kuliczkowska J, Leano R, PrzewlockaKosmala M, Marwick TH. Use of body weight and insulin resistance to select obese patients for echocardiographic assessment of subclinical left ventricular dysfunction. Am J Cardiol. 2008;101:1334-40.

40. Nadruz W Jr., Claggett B, Goncalves A, Querejeta-Roca G, Fernandes-Silva MM, Shah AM, et al. Smoking and cardiac structure and function in the elderly: the ARIC study (atherosclerosis risk in communities). Circ Cardiovasc Imaging 2016;9: e004950. 